\title{
Analysis of Fertility Pattern Through Mathematical Curves
}

\author{
Brijesh P. Singh ${ }^{1}$, Kushagra Gupta ${ }^{2}$, K. K. Singh ${ }^{3}$ \\ ${ }^{1}$ Faculty of Commerce \& DST-CIMS, Banaras Hindu University, Varanasi, India \\ ${ }^{2}$ Department of Statistics, Banaras Hindu University, Varanasi, India \\ ${ }^{3}$ Department of Statistics \& Centre for Population Studies, Banaras Hindu University, Varanasi, India
}

Email address:

kushagra.bhu.rath@gmail.com (K. Gupta)

\section{To cite this article:}

Brijesh P. Singh, Kushagra Gupta, K. K. Singh. Analysis of Fertility Pattern Through Mathematical Curves. American Journal of Theoretical and Applied Statistics. Vol. 4, No. 2, 2015, pp. 64-70. doi: 10.11648/j.ajtas.20150402.14

\begin{abstract}
The age-specific fertility curves normalized by total fertility can be considered as the density of the age at childbearing distribution. Generally the shape of age specific fertility rate changes from convex to concave after it reaches its maximum value. Proportion bearing children before age 35 may be interpreted as tempo of fertility and rest may be interpreted as excess fertility, which is risky for mother as well as child both. Thus, the purpose of this study is to observe the pattern of fertility over time and space keeping the above idea into consideration. To experience the modest change in fertility, the estimated total fertility rate, are computed for the data through simple mathematical model. For this purpose the secondary data on age-specific fertility rate and its forward and backward cumulative distributions have been considered. Also the validity of proposed models has been checked through appropriate technique.
\end{abstract}

Keywords: Age specific fertility rate, Mathematical Model, Polynomial Curve, Cross Validity Prediction Power, Shrinkage

\section{Introduction}

Demographic features of human population have direct relationship with social as well as biological factors. Fertility is one of the main demographic features of any population and the fertility analysis of human population is done usually by two ways. The first way is primarily concerned with the estimation of parameters of standard measures of fertility. Demographic factors like age at marriage, present family size, gender preference (Mahadevan, 1979; Bhasin, 1990; Ansari and John, 1998; Chachra and Bhasin, 1998; Bhasin and Nag, 2002; Singh et al, 1992; Nath et al, 1993) and socioeconomic factors like education, occupation, religion, contraceptive practice, etc. (Bhatia, 1970; Ansari and John, 1998; Singh.et.al 2001, 2002) are the determinants of desired family size and the generally considered ascause of the variation in fertility. Place of residence, family type, mass media exposure are some factor that indirectly plays an important role and it affects the fertility. The couple's decision about their next child affects the birth interval and indirectly this affect the fertility. Old age security also motivates higher fertility (Vlassof and Vlassof, 1980; Goody et al. 1981) and also parent's desire for more children directly correlated with their fear of losing them (Mysore Population Study, 1961; Preston, 1978). Desired family size depends on the relative utilities of economic benefits and the cost of upbringing children.

The second way of fertility analysis deals with graduating the fertility pattern through mathematical curves. Due to its simplicity, the modeling of fertilitypattern through different mathematical curves have attracted the interest of demographers and still the researcher who were working in the field of demography are using different mathematical curve to graduate the trend of fertility analysis. Among other reasons, the interest in fertilitymodeling through curves is due to the fact that it is helpful in population projection, which isvery useful for government planning.Fertility analysis plays an important role to measure the intensity of population growth.

It is widely known that the distribution of age-specific fertility rates has a typical shape over time common in all human populations. Fertility pattern of some developed countries have shown a deviation from the classical bell shaped curve. Some of the countries exhibit almost bimodal shape of age-specific fertility rates. This kind of pattern can also be easily captured by a mixture Model, assuming that two populations with different fertility patterns are mixed in one. The standard fertility shape depicting fertility according to age is zero values before menarche i.e. the 14 year of age, low but increasing positive values between 15-19 years, 
rising to a maximum between 20-29 age group, and then decreasing slowly to reach almost zero by age 50 years. Countries show inequalities with respect to the age where the fertility rates reaches a maximum and the variable speed with which the maximum is approached from the beginning and is then passed to reach the end of the fertility span.

In literature, a variety of mathematical and stochastic models have been proposed which have described the reproductive pattern of human population. Among the models used for representing the age-specific fertility pattern of populations, that do not show high early-age-specific fertility, several authors have provided models with accurate fits to the one-year age-specific fertility distributions. These include the Coale- Trussell function (Coale and Trussell, 1974; 1978), the Beta and Gamma distributions equivalent to the Pearson Type I and III curves respectively (Hoem et al., 1981), the Hadwiger distribution (Hadwiger, 1940; Gilje, 1969; Yntema, 1969), and cubic Splines (Hoem and Rennermalm, 1978; Gilks, 1986). Additionally fertility analysis have been done using some other curves such as Pearson Type 1 curve (Mitra, 1967; Romaniuk, 1973) and Type III curves (Nurul-Islam and Ali Mallick, 1987), the Brass procedures (Brass, 1974; 1978), the Gompertz curve (Wunsch, 1966; Murphy and Nagnur, 1972; Farid, 1973) and polynomial Models (Brass, 1960).

Ram (2004) made a comparison between fertility rates from the Indian registry system and those from the census using the own-children method for the period 1991-96. The total fertility rate for the period 1991-96, it is evaluated as 2.86 from the census data while that from the Indian registry system data it comes out to be 2.81. This shows a very similar level of estimated total fertility rate from the two sets of data sources. If the mean age of fertility is larger than the modal age, the distribution of age specific fertility rates can be reasonably well approximated by using the Pearsonian Type I curve (Verma and Loh, 1992; Verma et al., 1996). The models described above worked well for the data on single year age specific fertility rates, where there are a lot of information and variations (fluctuations) too. The models which are described above are quite reliable but some mathematical complications are there and thus not easy to find out the estimates.

The patterns of fertility of some developed countries show a deviation from the classic bell-shaped curve and it can be approximated by bimodal shape of age-specific fertility. This kind of pattern can easily be captured by a mixture model, assuming that two populations with different age-specific fertility rates combined in one. Chandola et al. (1999) proposed a mixture Hadwiger model with six parameters and Ortega Osona and Kohler (2000) pointed out that an additional parameter is needed, resulting in a sevenparameter model. Another proposal was made by Peristera and Kostaki (2007), who first defined a simple model based on a normal probability density function but with a different variance parameter for ages before and after the mean age, and then a normal mixture model with six parameters. The skew normal distribution and its generalization (Azzalini, $1985,2005)$ have been also suggested. Initially a three- parameter skew normal probability density function is defined where the skewness parameter allows the function to be asymmetric, like many fertility patterns. A skew normal distribution can be generalized by adding a further parameter to allow for a bimodal shape.

Some other mathematical Models have been developed to find out the fertility pattern with the help of the information of grouped age specific fertility rates. The grouped age specific fertility rate is more reliable because generally digit preference is available in the age of the females data and second advantage of this type of data is that it is easy accessible. For the grouped age specific data polynomial fitting have been done by demographers and the most recent work in this direction has been done for fitting age specific marital fertility rates of Bangladesh by Islam (2009) using polynomial model approach. He has suggested a simple third degree polynomial to justify the current fertility pattern of Bangladesh population.

India is a very vast country and has cultural, social and other diversity and thus taking India as a wholeto analyze fertility pattern through amodel is not quite justified. In this papera simple mathematical Model has been proposed to study the pattern of the grouped age specific fertility schedules by considering the data of rural and urban part of Uttar Pradeshas well as considering the data of the state Uttar Pradesh as a whole. The simple polynomial Model suggested by Islam (2009) to study the pattern of age specific fertility rate has also been studiedfor comparison purpose.

\section{Data and Methodology}

\subsection{Data Used}

To study the age specific fertility rates, the reliable data are taken from the National Family Health Survey (NFHS). For understanding the current situation of the fertility pattern, the recent third round of this NFHS has been considered for extracting the information on ASFR. In the NFHS-III data, the currently married females with age group 15-49 of the state Uttar Pradesh has been considered in the study and further it has beenclassified into two groups according to their place of residence. The two groups are whether the females are living in urban or rural part of the state. The group is classified to describe the fertility pattern of rural and urban states andto have an idea about the difference between them. The data is also used to check the suitability of the Model considered on three sets of data.

An important purpose of modeling the data is to clarify concepts, rather than to replicate an observed transition. Researchers, concerned with both abstract theorizing and concrete prediction, have adopted variations in the methodology. The social sciences are over-rich in descriptive theories that have limited practical application. The process of modeling itself can produce valuable personal insight on the subject being modeled. The act of translating a theory into a simulation requires making everything explicit and quickly exposes internal inconsistencies and gaps. 
Mathematical models bind theories to precise formulations and by doing so accentuate logical inconsistencies.

\subsection{Methodology}

\subsubsection{Polynomial Models}

By observing the scatter plot of age specific fertility rates of women of states Uttar Pradesh, it can be easily decided that the age specific fertility rates (ASFR) can be described through fitting polynomial models with respect to different ages in year. Keeping in view the nature of the data, it can be explained by third degree polynomial which is as follows:

Model I: The third degree polynomial of with respect to $x$

$$
y=a+b x+c x^{2}+d x^{3}
$$

Model II: The third degree polynomial of with respect to reciprocal of $x$

$$
y=a+(b / x)+\left(c / x^{2}\right)+\left(d / x^{3}\right)
$$

where $y$ is the age specific fertility rates and $x$ is the midpoint of the age intervals.

Model I is suggested by the Islam (2009) to describe the ASFR of Bangladesh data. In this paper a modified the modelhave been proposed which is modification of the model given by Islam (2009) taking into consideration the reciprocal of midpoint of age interval instead of taking the midpoint of age interval which is Model II. This model describes the ASFR well and gives better estimates which are more efficient than the estimate which is obtained by fitting Model I given by Islam (2009). Thus,by applying the proposedmodelone can get more reliable estimate of fertility parameters which can explain the pattern of fertility more accurately. The model fittings as well as the estimation of ASFR for the model I and model II is obtained with the help of statistical software SPSS v18.

\subsubsection{Model Validation of the Fitted Model}

\subsection{1. Cross Validity Prediction Power}

It is necessary to find out the estimate that how accurately a predictive model will perform in practice or to know how much the proposed Model is stable over population.In this respect an appropriate technique known as cross validity prediction power (CVPP) given by Herzberg (1969) have been utilized which is given as

$$
\rho_{v}^{2}=1-\frac{\left(n^{2}-1\right)(n-2)\left(1-r^{2}\right)}{n(n-p-1)(n-p-2)}
$$

wheren is the number of cases, $p$ is the number of explanatory variables in the Model and $r$ is the correlation between predicted and observed value of the dependent variable.

\subsubsection{Shrinkage}

The standard adjustment made in the coefficient of determination to compensate for the subjective effects of further sampling,the shrinkage of themodel is given as

$$
\text { Shrinkage }=\left|\rho_{v}{ }^{2}-r^{2}\right|
$$

where $\rho_{\mathrm{v}}{ }^{2}$ is cross validity prediction power $\& \mathrm{r}^{2}$ is the coefficient of determinationof the Model. Moreover, the stability of $r^{2}$ of the model isequal to (1- shrinkage).

\section{Results and Discussion}

Table 1 represents the age specific fertility rates for the females of Uttar Pradesh according to their place of residence.The females of Uttar Pradesh who are residing in urban areas have higher ASFR for each age intervals. The highest fertility is found in the age group of females 20-25 years in each group.

Figure 1 show the observed age specific fertility rates for state Uttar Pradeshaccording to residential status of female and also considering the state as a whole. The information on observed values of ASFR for different states is coming from the report of NFHS-III. The ASFRs for all combined femalealways lie within the ASFRs of the females living in rural and urban part of that states. The pattern of ASFR for different classifiedgroup and state as a whole are quite same and the ASFR increases slowly from age 15 years and the peak of the curve or maximum ASFR belongs to the females of who are in the age group 20-30 years and afterwards it declines sharply and approaches to zero as age of the female approaches to 50 years (bell shape).

Table 1. Current age specific fertility rates of females of Uttar Pradesh according to their residential status Uttar Pradesh (NFHS-III, 2005-06)

\begin{tabular}{llll}
\hline \multirow{2}{*}{ Age Group } & \multicolumn{3}{l}{ Uttar Pradesh } \\
\cline { 2 - 4 } & Total & Urban & Rural \\
\hline $15-19$ & 0.096 & 0.059 & 0.109 \\
$20-24$ & 0.268 & 0.207 & 0.289 \\
$25-29$ & 0.212 & 0.199 & 0.216 \\
$30-34$ & 0.112 & 0.084 & 0.123 \\
$35-39$ & 0.053 & 0.032 & 0.062 \\
$40-44$ & 0.019 & 0.010 & 0.022 \\
$45-49$ & 0.003 & 0.000 & 0.005 \\
\hline
\end{tabular}

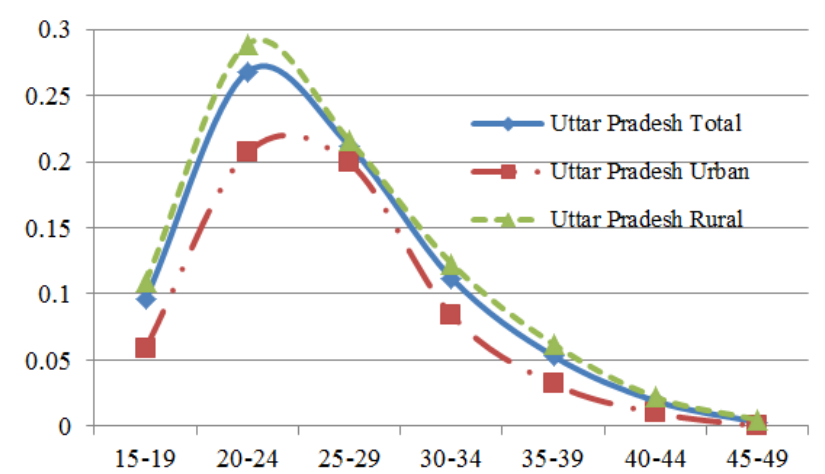

Figure 1. Graphical representation of age specific fertility rates of the females of Uttar Pradesh according to their residential status (NFHS-III Data)

\subsection{Analysis of Data for the State of Uttar Pradesh}

Let us consider a third degree polynomial to graduate the distribution of ASFR which is as follows: 


$$
y=a+b x+c x^{2}+d x^{3}
$$

(Model I)

For fitting the curve described by above equation to explain ASFR of Uttar Pradesh, the variables $\mathrm{x}$ is taken as midpoint of age group and the outcome variable is ASFR which is defined by variable y. Model I which is a third degree polynomial has been fitted to the given data and after fitting the Model I to observed data the coefficient of determination is obtained as 0.931 . This implies that the Model Iexplain about $93 \%$ variation of ASFR of the females of Uttar Pradesh. The adjusted coefficient of determination has been obtained and it takes value 0.862 and F-value for the same Model Iis 13.4508.

The equation of the curve is given by

$$
y=-2.019+0.226 x-0.007 x^{2}+7.00 E-05 x^{3}
$$

With Adj. $\mathrm{R}^{2}=0.862$

Let us consider a polynomial of third degree instead of variable $\mathrm{x}$ which is defined in Model $\mathrm{I}$, the reciprocal of the variable $\mathrm{x}$ i.e. $(1 / \mathrm{x})$ is considered and is defined as follows:

$$
y=a+(b / x)+\left(c / x^{2}\right)+\left(d / x^{3}\right)
$$

(Model II)

The above model has been proposed to find out the estimate of the parameters involved in the model by applying it on the data of observed ASFR of Uttar Pradesh data and these parameters are further utilized to predict ASFR of Uttar Pradesh. In this modelpredicting functionis a third degree polynomial of inverse of the mid-point of age group $(1 / \mathrm{x})$ and the outcome variable is ASFR and is shown by y. After applying Model II on the data the coefficient of determination is comes out to be 0.996which means thatModel II explains $99.6 \%$ variation of ASFR. The adjusted coefficient of determination has also calculated for the above model and it is found out to be 0.992 with F-value 262.158.

The equation of the curve is given by

$$
\begin{gathered}
y=0.358-50.834(1 / x)+2050.442\left(1 / x^{2}\right)-21929.849\left(1 / x^{3}\right) \\
\text { With Adj. } \mathrm{R}^{2}=0.992
\end{gathered}
$$

Table 2 explains the predicted value of ASFR for Uttar Pradesh with the help of polynomial represented by Model I and Model II. This table contains the age interval of the females in years, midpoint of corresponding age interval, observed ASFR as taken from Table 1 for Uttar Pradesh, predicted ASFR with the help of curve 1 and 2 and confidence limit at $95 \%$ CI for corresponding predicted ASFR by applyingboth the curves. The values of ASFR predicted by Model II gives more close result than the values predicted with the help of Model I. Predicted ASFR clearly shows that in the age group 20-30 years the highest fertility is obtained using Model I and if we are applying Model II, the

\begin{tabular}{|c|c|c|c|c|c|c|c|c|}
\hline \multirow{2}{*}{$\begin{array}{l}\text { Age-Interval } \\
\text { (in years) }\end{array}$} & \multirow{2}{*}{$\begin{array}{l}\text { Mid-point of } \\
\text { the age group }\end{array}$} & \multirow{2}{*}{$\begin{array}{l}\text { Observed } \\
\text { ASFR }\end{array}$} & \multicolumn{3}{|c|}{ Model I: $y=a+b x+c x^{2}+d x^{3}$} & \multicolumn{3}{|c|}{ Model II: $y=a+(b / x)+\left(c / x^{2}\right)+\left(d / x^{3}\right)$} \\
\hline & & & \multirow{2}{*}{$\begin{array}{l}\text { Predicted ASFR } \\
0.1123\end{array}$} & \multicolumn{2}{|c|}{ 95\% Confidence Limits } & \multirow{2}{*}{$\begin{array}{l}\text { Predicted ASFR } \\
0.0952\end{array}$} & \multicolumn{2}{|c|}{ 95\% Confidence Limits } \\
\hline $15-20$ & 17.5 & 0.096 & & 0.0000 & 0.2250 & & 0.0676 & 0.1227 \\
\hline $20-25$ & 22.5 & 0.268 & 0.2284 & 0.1497 & 0.3070 & 0.2740 & 0.2489 & 0.2991 \\
\hline $25-30$ & 27.5 & 0.212 & 0.2216 & 0.1430 & 0.3003 & 0.2002 & 0.1833 & 0.2170 \\
\hline $30-35$ & 32.5 & 0.112 & 0.1446 & 0.0771 & 0.2122 & 0.1166 & 0.0987 & 0.1345 \\
\hline $35-40$ & 37.5 & 0.053 & 0.0498 & 0.0000 & 0.1285 & 0.0570 & 0.0410 & 0.0730 \\
\hline $40-45$ & 42.5 & 0.019 & - & - & - & 0.0201 & 0.0049 & 0.0354 \\
\hline $45-50$ & 47.5 & 0.003 & 0.0167 & 0.0000 & 0.1294 & 0.0001 & 0.0000 & 0.0236 \\
\hline
\end{tabular}
highest value of predicted ASFR lies in the age group 20-25 years. The ASFR for age group 40-45 years is not explained if Model I is applied to the real data.

Table 2. Predicted values of ASFR utilizing Model I and Model II for the state Uttar Pradesh

Figure 2 shows the curve between age group (in years) and ASFR for observed value, estimated value with the help of Model I and Model II respectively. The figure clearly shows that Model IIfits the observed values more accurately than the values of predicted ASFR obtained from Model I.

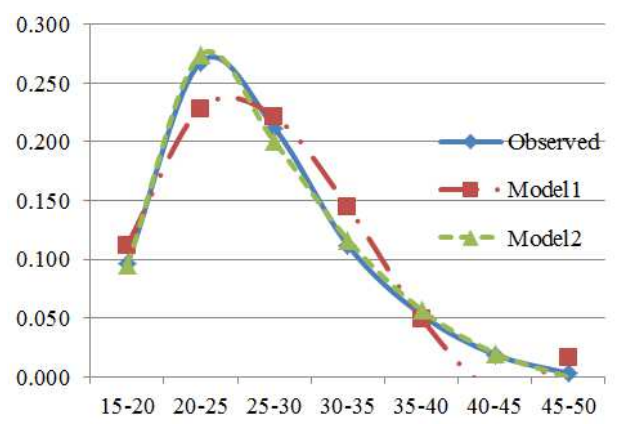

Figure 2. Plot of ASFR for Uttar Pradesh and Curve Fitting of Model I and Model II

\subsection{Analysis of the Urban Female Data of Uttar Pradesh}

In this section first Model I has been considered to explain the variation in ASFR for the females who are residing in urban part of Uttar Pradesh. As described in the Model, the variableused to explain fertility is mid-point of age group denoted by $\mathrm{x}$ and the outcome variable is ASFR denoted by $\mathrm{y}$. By applying the Model I on the data, coefficient of determination is obtained as 0.936 andthis implies that the Model I explains $93.6 \%$ variation of ASFR for the females belong to urban Uttar Pradesh. After applying the model to the data, the adjusted coefficient of determination is obtained as 0.871 with F-value is 14.552 .

The equation of the curve is given by

$$
y=-2.020+0.220 x-0.007 x^{2}+6.78 E-05 x^{3}
$$

With Adj. $\mathrm{R}^{2}=0.871$ 
Model II has also fitted to observe ASFR for the data of females ofurban Uttar Pradesh to observe the pattern of fertility in this region. The variables explaining age specific fertility is inverse of the mid-point of age group denoted by $(1 / x)$ and the predictor variable is ASFR which is defined by y. With the help of observed data, TheModel IIhas coefficient of determination 0.963 which means that the Model II explain $96.3 \%$ variation in the data of ASFR with the help of this explanatory variable. The adjusted coefficient of determination forModel II at given data is obtained as 0.926with F-value 25.954.

The equation of the curve is given by

$$
y=0.490-64.481(1 / x)+2510.311\left(1 / x^{2}\right)-26300.105\left(1 / x^{3}\right)
$$

$$
\text { With Adj. } \mathrm{R}^{2}=0.926
$$

Table 3 shows the predicted value of ASFR for the females residing in urban Uttar Pradesh with the help of third degree polynomial Model I and Model II. This table contains the age interval of the females, mid-point of corresponding age interval, observed ASFR for females of Uttar Pradesh living in urban area, predicted ASFR with the help of curve 3 and 4 and confidence limit at $95 \%$ CI for corresponding predicted ASFR for both curve 3 and curve 4 . It is worthwhile to mention that the curve 4 gives predicted value of ASFR which is closer to observed ASFR than the predicted values obtained from curve 3. If we apply Model I to the data then the predicted values clearly shows that the highest fertility has been obtained for the age group 20-25 and 25-30years and it is approximately same in both the age group, whereas, if Model II is applied for the same data set, it is observed that the predicted value of ASFRis maximum in the age group 2025 years from the given data. Again the drawback of Model Iis that the ASFR for the female of urban Uttar Pradesh in age group 40-45 years is unexplained.

\begin{tabular}{|c|c|c|c|c|c|c|c|c|}
\hline \multirow{3}{*}{$\begin{array}{l}\text { Age-Interval } \\
\text { (in years) } \\
15-20\end{array}$} & \multirow{2}{*}{$\begin{array}{l}\text { Mid-point of } \\
\text { the age group }\end{array}$} & \multirow{2}{*}{$\begin{array}{l}\text { Observed } \\
\text { ASFR }\end{array}$} & \multicolumn{3}{|c|}{ Model I: $y=a+b x+c x^{2}+d x^{3}$} & \multicolumn{3}{|c|}{ Model II: $y=a+(b / x)+\left(c / x^{2}\right)+\left(d / x^{3}\right)$} \\
\hline & & & \multirow{2}{*}{$\begin{array}{l}\text { Predicted ASFR } \\
0.0690\end{array}$} & \multicolumn{2}{|c|}{ 95\% Confidence Limits } & \multirow{2}{*}{$\begin{array}{l}\text { Predicted ASFR } \\
0.0567\end{array}$} & \multicolumn{2}{|c|}{ 95\% Confidence Limits } \\
\hline & 17.5 & 0.059 & & 0.0000 & 0.1634 & & 0.0000 & 0.1329 \\
\hline $20-25$ & 22.5 & 0.207 & 0.1880 & 0.1221 & 0.2539 & 0.2237 & 0.1542 & 0.2932 \\
\hline $25-30$ & 27.5 & 0.199 & 0.1878 & 0.1219 & 0.2537 & 0.1663 & 0.1197 & 0.2130 \\
\hline $30-35$ & 32.5 & 0.084 & 0.1194 & 0.0628 & 0.1760 & 0.0963 & 0.0467 & 0.1459 \\
\hline $35-40$ & 37.5 & 0.032 & 0.0335 & 0.0000 & 0.0994 & 0.0447 & 0.0003 & 0.0890 \\
\hline $40-45$ & 42.5 & 0.010 & - & - & - & 0.0114 & 0.0000 & 0.0537 \\
\hline $45-50$ & 47.5 & 0.000 & 0.0125 & 0.0000 & 0.1069 & 0.0001 & 0.0000 & 0.0576 \\
\hline
\end{tabular}

Table 3. Predicted values of ASFR utilizing Model I and Model II for Urban Uttar Pradesh

Figure 3 gives the plot of ASFR according to the age group of females in years. Three curves have been shown in this figure. First is age-group vs. observed ASFR, second is agegroup vs. estimated ASFR using Model I and last is agegroup vs. estimated ASFR using Model II. Both the curve obtained by Model I and Model II to predict ASFR are deviated from the plotted line of observed ASFR. But, the line which is drawn with the help of Model II to predict ASFR is closer than the line which is drawn with the help of Model I to predict the same ASFR.

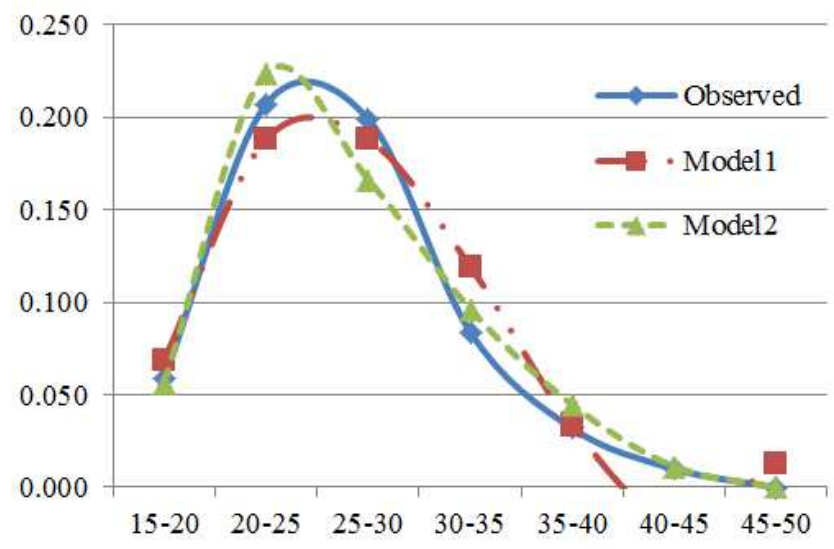

Figure 3. Curve of observed ASFR for Urban Uttar Pradesh and the curve of predicted ASFR by applying Model I and Model II

\subsection{Analysis of Rural Female data of Uttar Pradesh}

Model I has been utilized to find out the value of ASFR of rural part of Uttar Pradesh. In this Model, the variables explaining fertility is mid-point of age group (x) and the outcome variable is ASFR (y). After applying the Model I for the data of rural Uttar Pradesh, the coefficient of determination is comes out to be 0.925 . This implies that the Model Iexplain 92.5\% variation of ASFR for the females living in rural area of Uttar Pradesh with the help this explanatory variable. After applying Model I to the given data,the adjusted coefficient of determination is 0.850 and Fvalue is 12.333 .

The equation of the curve is given by

$$
y=-2.012+0.227 x-0.007 x^{2}+7.04 E-05 x^{3}
$$$$
\text { With Adj. } \mathrm{R}^{2}=0.850
$$

To observe the variation in ASFR of rural Uttar Pradesh, fitting of ASFR has been fitted to observed data of ASFR. Here the variables explanatory variable isinverse of the midpoint of age group $(1 / \mathrm{x})$ and the explained variable is ASFR (y). This Model has coefficient of determination 0.999 which means that the Model explain $99.9 \%$ variation of ASFR with the help of this explanatory variable. The adjusted coefficient of determination for the Model II at given data set is 0.999 and F-value is 2499.375 .

The equation of the curve is given by 


$$
y=0.524-68.054(1 / x)+2636.099\left(1 / x^{2}\right)-27517.680\left(1 / x^{3}\right)
$$

$$
\text { With Adj. } \mathrm{R}^{2}=0.999
$$

Table 4 shows the predicted value of ASFR for rural Uttar Pradesh with the help of third degree polynomial by applying Model I and Model II. This table contains the age interval of the females, mid-point of corresponding age interval, observed ASFR for the females of Uttar Pradesh living in rural area, predicted ASFR.The values of ASFR obtained with the help Model II givesquite closer result than the predicted values of ASFR obtained from Model I from the observed ASFR in rural Uttar Pradesh. Thus, the predicted ASFR obtained from Model IIdescribes better explanation in the variation of ASFR than the predicted ASFR from Model I. In Model I, predicted ASFR shows that the age group 20-25 years and 25-30 years has high fertility and it is unexplained for the age group 40-45 years for the females of rural Uttar Pradesh. In Model II maximum fertility is observed in the age group 20-25 years.

Table 4. Predicted values of ASFR utilizing Model I and Model II for rural Uttar Pradesh

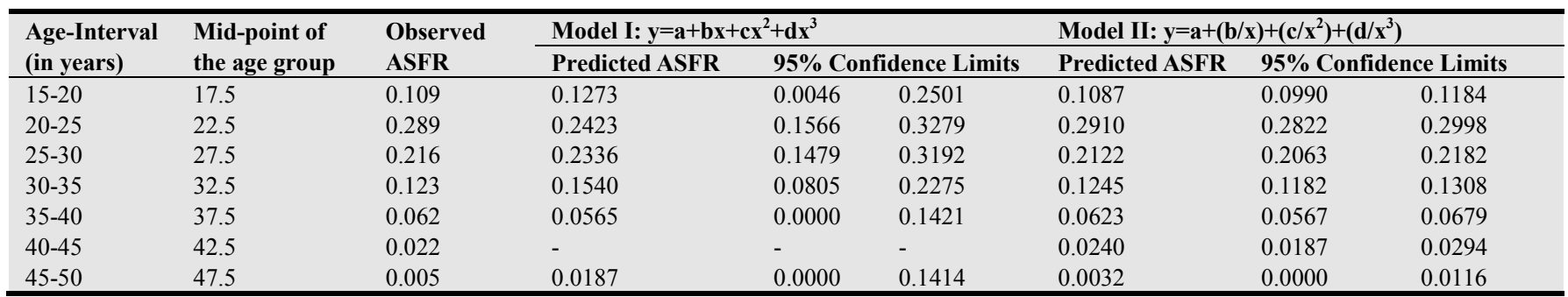

Figure 4 gives the plot between age-group and ASFRs. Three different curves have been shown in this figure. First is age-group vs. observed ASFR, second is age-group vs. estimated ASFR using Model I and last is age-group vs. estimated ASFR using Model II. Curve obtained from Model I shows departure from the observed value curve and values from Model II shows high accuracy and quite close or about to overlap to the observed value of ASFR for rural Uttar Pradesh.

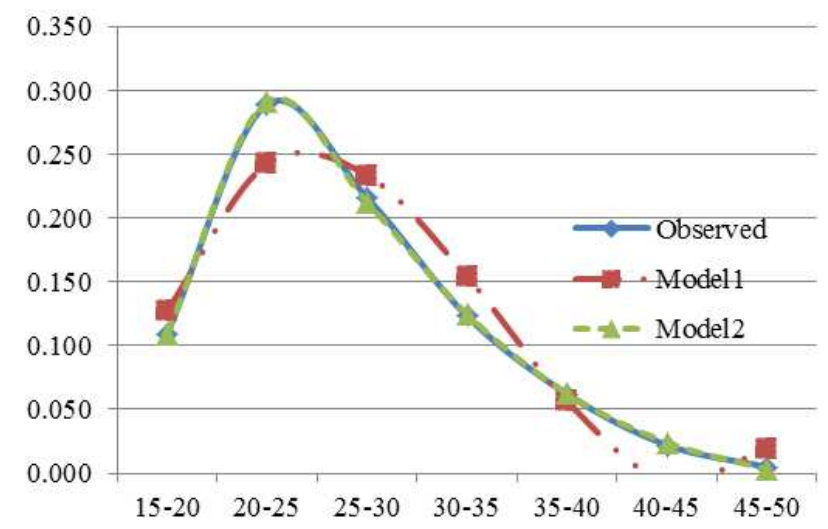

Figure 4. Scattered plot of observed ASFR for rural Uttar Pradesh and the curve of predicted ASFR by applying Model I and Model II

Table 5 explain the comparative study of Model I and Model II for different groupof females 1) Uttar Pradesh, 2) Urban Uttar Pradesh and 3) Rural Uttar Pradesh. In this table $\mathrm{n}$ is number of age group and $\mathrm{p}$ is number of order of polynomial equation. The model superiority is checked by giving the value of coefficient of determination, cross validity prediction power and shrinkage for each model in each group of females taken into the study. The results clearly shows that the Model II has better explaining the ASFR in each group of females in Uttar Pradesh as the classification consider in this study.
Table 5. Estimated cross validity prediction power (CVPP) $\rho_{v}^{2}$ and shrinkage of the predicted Models of ASFR for Uttar Pradesh as well as according to the residential status

\begin{tabular}{lllllll}
\hline Model for & & $\boldsymbol{n}$ & $\boldsymbol{p}$ & $\boldsymbol{r}^{2}$ & $\rho_{v}^{2}$ & Shrinkage \\
\hline \multirow{2}{*}{ ASFR } & Model I & 7 & 3 & 0.9308 & 0.6044 & 0.3264 \\
& Model II & 7 & 3 & 0.9962 & 0.9782 & 0.0180 \\
\multirow{2}{*}{ ASFR (Urban) } & Model I & 7 & 3 & 0.9357 & 0.6324 & 0.3033 \\
& Model II & 7 & 3 & 0.9629 & 0.8879 & 0.0750 \\
\multirow{2}{*}{ ASFR (Rural) } & Model I & 7 & 3 & 0.9250 & 0.5714 & 0.3536 \\
& Model II & 7 & 3 & 0.9996 & 0.9975 & 0.0021 \\
\hline
\end{tabular}

\section{Conclusion}

In introduction, it has been explained that there are several methods to graduate the ASFR. Some of them are stochastic and some are mathematical in nature with higher number of parameters. In those model, it is difficult toestimateand explanation of these parameters. Thus, the objective of this paper is to suggest a simple technique which explains the graduation of ASFR without much complication.

From this study, it can be conclude that by taking third degree polynomial with inverse of age of female gives better estimate of ASFR and explain the variations of the data well. It is worthwhile to mention that the Model I can't obtain the justified predicted value for the age interval 40-45 years but Model II gives justified estimated values of ASFR for this age interval. Thus,Model II explains better and can be further used to find the fertility changes over age of the females. The applicability of proposed Model (Model II) is not limited to the state level estimation of ASFR. It can also be used to estimation ASFR for place of residential dividend.

\section{References}

[1] Asari, V.G. and John, C. (1998). "Determinants of desired family size in Kerala." Demography India, 27, 369-381. 
[2] Azzalini, A. (1985). "A class of distributions which includes the normal ones." Scand. J. Statist., 12, 171-178.

[3] Azzalini, A. (2005) "The skew-normal distribution and related multivariate families (with discussion)." Scand. J.Statist., 32, 159-200.

[4] Bhasin, M. K. and Nag, S. (2002). "A Demographic profile of the people of Jammu and Kashmir: Estimates, trends and differentials in fertility." Journal of Human Ecology, 13, 57112 .

[5] Bhasin, V. (1990). "Habitat, Habitation and Health in the Himalayas. " Kamla Raj Enterprises, Delhi.

[6] Bhatia, J.C. (1970). "Prevalent knowledge and attitude of males towards family planning in a Punjab village." Journal of Family Welfare, 16, 3-14.

[7] Brass, W. (1960). "The graduation of fertility distributions by polynomial functions."Population Studies, 14: 148-162.

[8] Brass, W. (1974). "Perspectives in Population Prediction: Illustrated by the Statistics ofEngland and Wales (with discussion)." Journal of the Royal Statistical SocietyA, 137: 532-583.

[9] Brass, W. (1978). "Population Projections for Planning and Policy." Papers of the East- West Population Institute, No 55. Honolulu, Hawaii.

[10] Chachra, S. P. and Bhasin, M. K. (1998). "Anthropodemographic study among the caste and tribal groups of central Himalayas: fertility differentials and determinants." Journal of Human Ecology, 9, 417-429.

[11] Chandola,T., Coleman,D. and Hiorns, R.W. (1999). "Recent European fertility patterns: fitting curves to 'distorted'distributions." Popln Stud., 53, 317-329.

[12] Coale, A.J. and Trussell, T. J. (1974). "Model fertility schedules: variations in the age structure of childbearing in human populations." Population Index, 40, 2: 185-258.

[13] Coale, A.J. and Trussell, T. J. (1978). "Technical note: finding the two parameters that specify a model schedule of marital fertility." Population Index, 44, 2: 203-214.

[14] Das, N. (1984). "Sex preference pattern and its stability in India: 1970-80." Demography India, 13, 108-119.

[15] Farid, S. M. (1973). "On the pattern of cohort fertility." Population Studies, 27: 159-168.

[16] Gilje, E. (1969). "Fitting curves to age-specific fertility rates: some examples." Statistical Review of the Swedish National Central Bureau of Statistics III, 7:118-134.

[17] Gilks, W. R. (1986). "The relationship between birth history and current fertility indeveloping countries", Population Studies, 40.

[18] Goody, J. R., Duly, C. J., Beeson, I. and Harrison, G. (1981). "Implicit sex preferences: A comparative study." Journal of Biosocial Sciences, 13, 455-466.

[19] Hadwiger, H. (1940). "Eineanalytischereprodutions-funktion fur biologischeGesamtheiten.",SkandinaviskAktuarietidskrift, 23, 101-113.

[20] Herzberg, P. A. (1969). "The parameter of cross validation." Psyshometrika (Monograph Supplement, No. 16).
[21] Hoem, J. M. and Rennermalm, B. (1978). "On the statistical theory of graduation by Splines", University of Copenhagen, Laboratory of Actuarial Mathematics. Working Paper No. 14.

[22] Hoem, J. M., Madsen, D., Nielsen, J. L., Ohlsen, E., Hansen, H. O., Rennermalm, B. (1981). "Experiments in modelling recent Danish fertility curves.",Demography, 18: 231-244.

[23] Islam, R. (2009). "Mathematical Modeling of Age Specific Marital Fertility Rates of Bangladesh", Research Journal of Mathematics and Statictics 1(1): 19-22, 2009.

[24] Mahadevan, K. (1979). "Sociology of Fertility: Determinants of Fertility Differentials in South India." Sterling Publishers, New Delhi, India.

[25] Mitra, S. (1967). "The pattern of age-specific fertility rates.".Demography, 4: 894-906.

[26] Murphy, E. M. and Nagnur, D.N. (1972). "A Gompertz fit that fits: Applications toCanadian Fertility Patterns." Demography, 9: $35-50$.

[27] Mysore Population Study. (1961). "Sponsored by United Nations and Government of India." Mysore Population Study.

[28] Nurul Islam, M. and Mallick S. A. (1987). "On the use of a truncated Pearsonian TypeIII curve in fertility estimation.",Djaka University Studies, Part B Science, 35,1: 23-32.

[29] Ortega Osona, J. A. and Kohler, H.-P. (2000). “A comment on "Recent European fertility patterns: fitting curvesto 'distorted' distributions", by T. Chandola, D. A. Coleman and R. W. Hiorns". Popln Stud., 54, 347-349.

[30] Peristera, P. and Kostaki, A. (2007) "Modelling fertility in modern populations." Demogr. Res., 16, 141-194.

[31] Preston, H. S. (1978). "The Effects of Infant and Child Mortality on Fertility". Academic Press, New York.

[32] Romaniuk, A. (1973). "A three parameter model for birth projections." Population Studies, 27, 3: 467-478.

[33] Verma, R.B.P. and S. Loh. 1992. "Evaluation of Pearsonian Type I Curve of Fertility by Age of Mother for Canada, Provinces and Territories, 1980-1989". Paper presented at the Canadian Population Society meeting, Charlottetown, P.E.I., June 2-5.

[34] Verma, R.B.P., S. Loh, S.Y. Dai, and D. Ford. 1996. "Fertility Projections for Canada, Provinces and Territories, 1993-2016". Statistics Canada, Catalogue no. 91F001MIE, Ottawa.

[35] Vlassof, C. (1990). "Fertility intentions and subsequent behavior: A longitudinal study in rural India." Studies in Family Planning, 21, 216-225.

[36] Vlassof, M. and Vlassof, C. (1980). "Old age security and the utility of children in rural India." Population Studies, 34, 487499.

[37] Wunsch, G. (1966). "Courbes de Gompertz et prespectives de fecondirte.”, RecherchesEconomiques de Louvain, 6: 457-468.

[38] Yntema, L. (1969). "On Hadwiger's fertility function.", Statistical Review of the Swedish National Central Bureau of Statistics III, 7, 113-117. 